\title{
Three-dimensional motion analysis of ten common Asian sitting positions in daily living and factors affect range of hip motions
}

Phob Ganokroj, Jirayu Chaowalitwong, Pichitpol Kerdsomnuek, Narumol Sudjai, Pisit Lertwanich and Bavornrat Vanadurongwan ${ }^{*}$

\begin{abstract}
Background: Sitting involves many activities of daily life and requires most motion in the hip joint. Asians have more hip flexion and external rotation motions than Westerners owing to cultural and lifestyle differences. Being aware of the normal range of hip motion is essential in clinical practice. Limited research has focused on the hip motions of common sitting positions. The objective was to determine the hip motions of 10 common sitting positions, and to determine whether gender or being overweight affects the range of hip motions.

Methods: An experimental cross-sectional study was conducted to determine hip motions by using a standard, three-dimensional, motion-analysis system. Healthy subjects performed 10 sitting positions during 3 trials. All hipkinematic data were measured on the dominant leg of each participant, except for the right- and left-monk positions (both hips were analyzed). Density plots were constructed and statistical analyses were performed to detect the differences between groups (male and female; non-overweight and overweight).

Results: The 48 participants comprised 24 males and 24 females. Most were right-leg dominant (45 participants, 93.8\%). Of the 22 participants in the overweight group (body mass index $\geq 23 \mathrm{~kg} / \mathrm{m}^{2}$ ), 18 (75\%) were male. Squatting showed the highest flexion angle $\left(99.7^{\circ}, 47.3^{\circ}-122^{\circ}\right)$. Cross-legged sitting had the highest abduction angle $\left(28.9^{\circ}, 9.9^{\circ}-45.7^{\circ}\right)$ and the largest external rotation angle $\left(62^{\circ}, 37.6^{\circ}-81.7^{\circ}\right)$. In the female group, there were trends toward a greater flexion angle ( 4 out of 10 sitting positions) and a smaller abduction angle ( 6 out of 9 positions), with $P$ values $<0.05$. As to body weight, the overweight participants had a smaller flexion angle but a greater abduction angle, with 5 out of 9 positions having a $P$ value $<0.05$. Kinematic data of the transverse plane revealed that the heterogeneity of the rotational angles depended on the sitting position.
\end{abstract}

Conclusions: This study provided the functional hip motions of common Asian sitting positions. The kinematic data can be utilized in clinical practice as reference values to determine safe positions. Gender and being overweight affected the hip angles in the sagittal and frontal planes.

* Correspondence: bavornrat.van@mahidol.ac.th

Department of Orthopaedic Surgery, Faculty of Medicine Siriraj Hospital, Mahidol University, Bangkok, 2 Prannok Road, Bangkok Noi, Bangkok 10700, Thailand

(c) The Author(s). 2021 Open Access This article is licensed under a Creative Commons Attribution 4.0 International License, which permits use, sharing, adaptation, distribution and reproduction in any medium or format, as long as you give appropriate credit to the original author(s) and the source, provide a link to the Creative Commons licence, and indicate if changes were made. The images or other third party material in this article are included in the article's Creative Commons licence, unless indicated otherwise in a credit line to the material. If material is not included in the article's Creative Commons licence and your intended use is not permitted by statutory regulation or exceeds the permitted use, you will need to obtain permission directly from the copyright holder. To view a copy of this licence, visit http://creativecommons.org/licenses/by/4.0/. The Creative Commons Public Domain Dedication waiver (http://creativecommons.org/publicdomain/zero/1.0/) applies to the data made available in this article, unless otherwise stated in a credit line to the data. 
Trial registration: Number TCTR20181021004, retrospectively registered at the Thai Clinical Trials Registry (http//: www.clinicaltrials.in.th).

Keywords: Activities of daily living, Angle, Gender, Hip, Kinematic study, Overweight, Range of motion, Sitting position, Squatting, Three-dimensional motion analysis

\section{Background}

Sitting is an essential human resting position and involves many activities of daily living (ADLs), such as sitting on a chair, using a toilet, and squatting. Sitting requires joint coordination between the hips, knees, and ankles, especially for the hip range of motion (ROM) [1]. Asians have more hip flexion and external rotation ROM angles than Western people. This may result from the differences in their cultures and lifestyles $[2,3]$. Squatting requires a high degree of hip movement, such as hip flexion, abduction, and external rotation [1]. Asians commonly squat at least once a day while performing their ADLs or using an Asian-style toilet [1]. [2] Though Westerners do not frequently squat during their ADLs, they use significant hip motion while tying shoelaces, ascending and descending stairs, or lifting objects [4].

It is essential for clinical practitioners to be aware of the normal range of hip motion in the common sitting positions of the ADLs. This basic knowledge can contribute to the development of implants or prostheses that enhance patients' lifestyles, or to the determination of the safe positions in rehabilitation programs following surgery $[1,5]$. For specific hip disorders like femoroacetabular impingement syndrome, this knowledge can assist patients to avoid the aggravating activities (particular sitting positions) that involve a great amount of flexion, adduction, or internal rotation [6]. However, there has been limited research focusing on the hip motions of the common sitting positions that are employed during the ADLs. Moreover, there are differences between the published studies in terms of the sitting positions, measurements, and analytical methods utilized [7-10].. The objective of the present research was to determine the hip ROMs for 10 standard sitting positions used during the ADLs. The authors compared the hip ROMs of healthy male and female subjects for each of a set of predefined sitting positions. The hypothesis was that gender and being overweight would influence the hip ROMs.

\section{Methods}

Before commencement of this research, its protocol was approved by the Institutional Review Board. The work was registered at the Thai Clinical Trials Registry (TCTR20181021004). The study was performed at a motion analysis laboratory at the authors' facility. The authors enrolled healthy subjects between 18 and 35 years of age. The participants were required to read an information sheet and give written, informed consent. All had no pain or limitations associated with their hip, knee, or ankle motions. The exclusion criteria were: (1) a history of lower extremity fracture; (2) previous lower extremity surgery (hip, knee, or ankle surgery); (3) the presence of any neuromuscular disorder or an impaired balance; (4) pregnancy; (5) a body mass index (BMI) of $>30 \mathrm{~kg} / \mathrm{m}^{2}$; and (6) an inability to perform all 10 sitting positions due to discomfort.

\section{Three-dimensional motion analysis (3DMA)}

All subjects wore short trousers to enable the secure attachment of reflective markers. Fifteen reflective markers were attached at the following anatomical landmarks: both anterior superior iliac spines (ASIS); the distal lateral femoral condyle; the midpoint between the imaginary line from the greater trochanter to the distal lateral femoral condyle; the distal medial femoral condyle; the midpoint between the imaginary line from the distal lateral femoral condyle to the lateral malleolii; the medial and lateral malleoli; and the sacrum. Eight optoelectronic cameras (Motion Analysis Corp., Santa Rosa, CA, USA) were used to record three-dimensional kinematic data at a sampling rate of $100 \mathrm{~Hz}$. The authors used the Helen Hayes marker model and methods for determining the hip joint center published by Bell et al., which is used widely for measuring kinematics data accurately [11-14]..

Cortex software (Motion Analysis Corp., Santa Rosa, CA, USA) was used to track and process the raw kinematic data filtered using a Butterworth low-pass filter, with a cutoff frequency of $6 \mathrm{~Hz}$. The hip angles were the maximum points achieved while the subjects were sitting still and comfortably. The hip ROM was analyzed using a Cardan rotation sequence of $x-y-z$. The local $x$-, $y$-, and $z$-axes corresponded to the flexion/extension, abduction/adduction, and internal/external rotation of the hip joint. Kinematic data were set to positive for the flexion, abduction, and external rotation motions. During the measurement, all the skin markers were confirmed for optimal placement.

\section{Calibrating the system}

The calibration was done before recording threedimensional kinematic data. There was a two-step process of calibration. First, the seed calibration step 

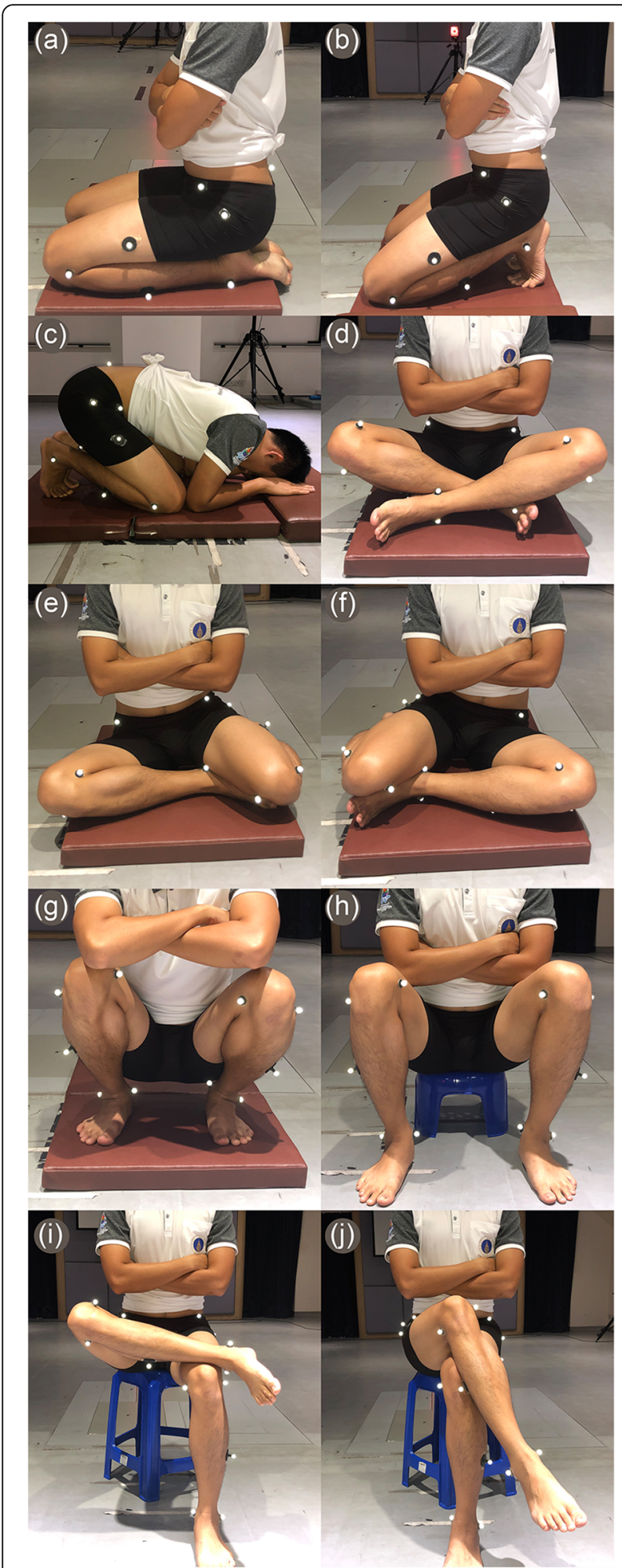

Fig. 1 Photographs of the 10 sitting positions: A) kneeling plantarflexed; b) kneeling dorsi-flexed; C) benjangkapradit prostration; D) cross-legged; E) left-monk; F) right-monk; $\mathbf{G ) ~ s q u a t t i n g ; ~} \mathbf{H}$ ) sitting on step stool; I) figure-four; and $\mathbf{J}$ ) standard leg-cross
Table 1 Demographic data

\begin{tabular}{lllll}
\hline Characteristic & $\begin{array}{l}\text { Total } \\
(\boldsymbol{n}=\mathbf{4 8})\end{array}$ & $\begin{array}{l}\text { Male } \\
(\boldsymbol{n}=\mathbf{2 4})\end{array}$ & $\begin{array}{l}\text { Female } \\
(\boldsymbol{n}=\mathbf{2 4})\end{array}$ & $\boldsymbol{P}$ value \\
\hline Age (year) & $26.5 \pm 4.0$ & $26.2 \pm 3.8$ & $26.8 \pm 4.2$ & 0.595 \\
Height $(\mathrm{cm})$ & $167.1 \pm 9.1$ & $174.2 \pm 5.9$ & $159.9 \pm 5.4$ & $<0.001^{*}$ \\
Body weight $(\mathrm{kg})$ & $63.1 \pm 12.4$ & $73.2 \pm 6.8$ & $52.9 \pm 7.2$ & $<0.001^{*}$ \\
BMl $\left(\mathrm{kg} / \mathrm{m}^{2}\right)$ & $22.4 \pm 3.0$ & $24.1 \pm 2.2$ & $20.7 \pm 2.6$ & $<0.001^{*}$
\end{tabular}

$\mathrm{BMI}$, body mass index

The $P$ values were for Student's t-test.

The asterisk $\left(^{*}\right)$ denotes a statistically significant difference between two groups.

defined the origin of a coordinate system and orientation of the axes system by using the L-frame placed on the volume of the study. Second, a wand calibration defined the validity of the marker position by using the wand marker waving side to side and up and down through the volume. In this study, the wand length distance was $500 \mathrm{~mm}$. Therefore, the calibration was acceptable when the wand length average was $500 \mathrm{~mm}$, and the deviation was lower than $0.5 \mathrm{~mm}$ for accurate three-dimensional data measurement.

\section{Intervention and measurements}

The primary demographic data (age, sex, weight, height, and BMI) were recorded. To determine leg dominance, subjects were asked, "If you kicked a ball at a target, which leg would you use to kick the ball?" [15].

All subjects performed the following 10 sitting position: (a) kneeling plantar-flexed; (b) kneeling dorsiflexed; (c) Benjangkapradit prostration; (d) cross-legged; (e) left-monk; (f) right-monk; (g) squatting; (h) sitting on a step stool; (i) figure-four; and (j) standard leg-cross. (Fig. 1A-J). In Asia, all of the positions are commonly used in the ADLs, while resting, and during social and religious activities.

Before conducting the research, the subjects were shown the correct posture for each of the aforementioned sitting positions and allowed to practice them. The subjects were instructed to hold each sitting position for at least $3 \mathrm{~s}$ to enable measurement of angles by the 3DMA equipment. All hip kinematic data were measured on the participant's dominant leg, except for the

Table 2 The number and percentage of participants, stratified by the BMI categories for adult Asian populations

\begin{tabular}{llll}
\hline Characteristic & $\begin{array}{l}\text { Non-overweight } \\
\left(\mathbf{B M I}<\mathbf{2 3} \mathbf{~ k g} / \mathbf{m}^{2}\right) \\
(\boldsymbol{n}=\mathbf{2 6})\end{array}$ & $\begin{array}{l}\text { Overweight } \\
\left(\mathbf{B M I} \geq \mathbf{2 3} \mathbf{~ k g} / \mathbf{m}^{\mathbf{2}}\right)\end{array}$ & $\begin{array}{l}\boldsymbol{P} \text { value } \\
(\boldsymbol{n}=\mathbf{2 2})\end{array}$ \\
\hline Male $(n=24)$ & $6(25.0 \%)$ & $18(75.0 \%)$ & $<0.001^{*}$ \\
Female $(n=24)$ & $20(83.3 \%)$ & $4(16.7 \%)$ & \\
\hline
\end{tabular}

BMI, body mass index.

The $P$ value was for the Chi-squared test.

The asterisk $\left({ }^{*}\right)$ denotes a statistically significant difference between two groups. 
Table 3 The measured kinematics of the hips of all participants, stratified by gender

\begin{tabular}{|c|c|c|c|c|}
\hline $\begin{array}{l}\text { Kinematic data of each } \\
\text { sitting position }\end{array}$ & $\begin{array}{l}\text { Total } \\
\text { Median degrees } \\
(n=48) \\
\end{array}$ & $\begin{array}{l}\text { Males } \\
\text { Median (range) degrees } \\
(n=24)\end{array}$ & $\begin{array}{l}\text { Females } \\
\text { Median (range) degrees } \\
(n=24)\end{array}$ & $P$ value \\
\hline \multicolumn{5}{|l|}{ Flexion (+) / Extension (-) } \\
\hline Kneeling plantar-flexed & 67.4 & 67.1 (38.7 to 79.2 ) & $67.4(44.1$ to 86.1$)$ & 0.695 \\
\hline Kneeling dorsi-flexed & 51.8 & 51.9 (29.9 to 60.3$)$ & 49.4 (32.4 to 66.7$)$ & 0.926 \\
\hline Benjangkapradit prostration & 95.3 & 89.3 (52.5 to 108.7$)$ & $101.6(88.0$ to 114.9$)$ & $<0.001^{*}$ \\
\hline Cross-legged & 87.7 & 87.0 (60.2 to 105.6$)$ & 89.7 (73.0 to 105.4$)$ & 0.257 \\
\hline \multicolumn{5}{|l|}{ Left-monk } \\
\hline Left hip & 64.6 & 55.9 (19.0 to 80.5) & $70.0(44.4$ to 79.2$)$ & $<0.001^{*}$ \\
\hline Right hip & 80.3 & 81.1 (55.4 to 94.5$)$ & 80.2 (63.6 to 93.0$)$ & 0.789 \\
\hline \multicolumn{5}{|l|}{ Right-monk } \\
\hline Left hip & 79.1 & 79.4 (60.1 to 96.6) & 79.1 (61.9 to 90.5$)$ & 0.433 \\
\hline Right hip & 65.5 & 58.9 (28.1 to 79.6$)$ & 69.4 (45.5 to 79.8$)$ & $0.032^{*}$ \\
\hline Squatting & 99.7 & 94.9 (47.3 to 122.0$)$ & $102.9(87.1$ to 115.4$)$ & $0.003^{*}$ \\
\hline Sitting on a step stool & 89.7 & 88.1 (44.9 to 101.9 ) & 90.9 (74.4 to 101.6$)$ & 0.089 \\
\hline Figure-four & 83.3 & 83.1 (58.5 to 104.5$)$ & 83.6 (69.6 to 99.7) & 0.984 \\
\hline Standard leg-cross & 80.0 & 80.8 (58.4 to 96.4 ) & 80.0 (61.5 to 93.3$)$ & 0.386 \\
\hline \multicolumn{5}{|l|}{ Abduction (+) / Adduction (-) } \\
\hline Kneeling plantar-flexed & 4.3 & $7.4(-6.0$ to 18.1$)$ & $3.5(-8.4$ to 12.9$)$ & $0.048^{*}$ \\
\hline Kneeling dorsi-flexed & 7.2 & $7.8(-1.1$ to 20.4$)$ & $5.6(-4.1$ to 13.9$)$ & $0.070^{*}$ \\
\hline Benjangkapradit prostration & 4.0 & $4.3(-10.3$ to 23.7$)$ & $3.6(-7.8$ to 24.9$)$ & 0.248 \\
\hline Cross-legged & 28.9 & $28.9(9.9$ to 45.7$)$ & 29.0 (10.4 to 44.3$)$ & 0.773 \\
\hline \multicolumn{5}{|l|}{ Left-monk } \\
\hline Left hip & 16.4 & $23.3(-1.2$ to 55.8$)$ & $11.9(-6.4$ to 21.6$)$ & $<0.001^{*}$ \\
\hline Right hip & 8.0 & $10.5(-5.0$ to 30.7$)$ & $6.7(-4.8$ to 21.8$)$ & 0.105 \\
\hline \multicolumn{5}{|l|}{ Right-monk } \\
\hline Left hip & 7.5 & $11.9(-8.5$ to 29.4$)$ & $4.4(-7.5$ to 14.3$)$ & $0.009^{*}$ \\
\hline Right hip & 17.5 & $22.3(9.2$ to 38.9$)$ & $13.7(-8.4$ to 30.7$)$ & $0.001^{*}$ \\
\hline Squatting & 8.1 & $12.5(-5.1$ to 34.3$)$ & $5.2(-6.5$ to 20.6$)$ & $0.018^{*}$ \\
\hline Sitting on a step stool & 11.5 & $14.8(-0.1$ to 31.5$)$ & $4.3(-6.0$ to 17.8$)$ & $<0.001^{*}$ \\
\hline Figure-four & 16.5 & $16.9(2.5$ to 35.2$)$ & $15.8(10.1$ to 28.7$)$ & 0.757 \\
\hline Standard leg-cross & -10.5 & $-6.9(-19.9$ to 6.0$)$ & $-12.5(-21.7$ to 6.7$)$ & $0.012^{*}$ \\
\hline \multicolumn{5}{|c|}{ External rotation (+) / Internal rotation (-) } \\
\hline Kneeling plantar-flexed & 1.5 & $1.1(-8.1$ to 20.8$)$ & $1.8(-6.3$ to 16.6$)$ & 0.734 \\
\hline Kneeling dorsi-flexed & 8.8 & $9.6(0.4$ to 15.9$)$ & $6.7(-8.3$ to 22.0$)$ & 0.359 \\
\hline Benjangkapradit prostration & 2.4 & $7.6(-10.8$ to 15.5$)$ & $-2.0(-18.2$ to 12.1$)$ & $0.001^{*}$ \\
\hline Cross-legged & 62.0 & 61.2 (37.6 to 73.5 ) & 63.6 (40.7 to 81.7$)$ & 0.332 \\
\hline \multicolumn{5}{|l|}{ Left-monk } \\
\hline Left hip & -37.5 & $-33.7(-51.1$ to -5.2$)$ & $-40.6(-54.5$ to -24.8$)$ & $0.014^{*}$ \\
\hline Right hip & 48.3 & 47.2 (18.7 to 62.5$)$ & 50.8 (33.9 to 62.2$)$ & $0.034^{*}$ \\
\hline \multicolumn{5}{|l|}{ Right-monk } \\
\hline Left hip & 47.7 & 47.1 (27.7 to 58.3$)$ & 49.4 (42.5 to 58.9$)$ & 0.101 \\
\hline Right hip & -37.0 & $-35.0(-51.9$ to -4.7$)$ & $-37.9(-52.3$ to -12.0$)$ & 0.112 \\
\hline Squatting & -5.4 & $-5.7(-24.5$ to 7.7$)$ & $-3.4(-20.0$ to 5.8$)$ & 0.445 \\
\hline Sitting on a step stool & -5.3 & $-6.9(-15.9$ to 9.3$)$ & $-3.3(-11.0$ to 6.8$)$ & $0.011^{*}$ \\
\hline Figure-four & 55.2 & 53.6 (42.9 to 68.6$)$ & 56.9 (35.1 to 75.7$)$ & 0.578 \\
\hline Standard leg-cross & 27.0 & 32.0 (14.9 to 63.7$)$ & 25.0 (2.9 to 48.4$)$ & 0.059 \\
\hline
\end{tabular}


Table 4 The measured kinematics of the hips of all participants, stratified by BMI

\begin{tabular}{|c|c|c|c|}
\hline $\begin{array}{l}\text { Kinematic data of each } \\
\text { sitting position }\end{array}$ & $\begin{array}{l}\text { Non-overweight } \\
\text { Median (range) } \\
\text { degrees } \\
(n=26)\end{array}$ & $\begin{array}{l}\text { Overweight } \\
\text { Median (range) } \\
\text { degrees } \\
(n=22)\end{array}$ & $P$ value \\
\hline \multicolumn{4}{|l|}{ Flexion (+) / Extension (-) } \\
\hline Kneeling plantar-flexed & 67.4 (38.6 to 86.1$)$ & $67.1(53.7$ to 79.2$)$ & 0.619 \\
\hline Kneeling dorsi-flexed & 52.4 (29.9 to 66.7$)$ & 50.4 (38.0 to 60.3$)$ & 0.346 \\
\hline Benjangkapradit prostration & 99.8 (52.5 to 114.9$)$ & 91.6 (61.9 to 108.7$)$ & $0.004^{*}$ \\
\hline Cross-legged & $85.9(60.2$ to 105.4$)$ & 92.0 (62.8 to 105.6$)$ & 0.207 \\
\hline \multicolumn{4}{|l|}{ Left monk } \\
\hline Left hip & $67.9(19.0$ to 79.2$)$ & $63.2(24.3$ to 80.5$)$ & 0.077 \\
\hline Right hip & 79.8 (55.4 to 93.0$)$ & $81.8(66.4$ to 94.5$)$ & 0.116 \\
\hline \multicolumn{4}{|l|}{ Right monk } \\
\hline Left hip & 78.8 (60.1 to 90.5$)$ & 79.8 (67.7 to 96.6$)$ & 0.185 \\
\hline Right hip & $66.9(28.1$ to 79.8$)$ & 63.7 (39.1 to 79.6$)$ & 0.649 \\
\hline Squatting & $102.5(47.3$ to 115.4$)$ & 97.2 (48.7 to 122.0$)$ & $0.040^{*}$ \\
\hline Sitting on a step stool & 90.5 (55.5 to 101.6) & 88.1 (44.9 to 101.9$)$ & 0.242 \\
\hline Figure-four & $80.3(58.5$ to 99.7$)$ & 83.9 (72.5 to 104.5$)$ & 0.166 \\
\hline Standard leg-cross & 78.5 (58.4 to 93.3$)$ & 83.8 (66.8 to 96.4$)$ & $0.005^{*}$ \\
\hline \multicolumn{4}{|l|}{ Abduction (+) / Adduction (-) } \\
\hline Kneeling plantar-flexed & $3.2(-8.4$ to 12.9$)$ & $6.8(-6.0$ to 18.1$)$ & $0.023^{*}$ \\
\hline Kneeling dorsi-flexed & $6.4(-4.1$ to 14.9$)$ & $7.8(-1.1$ to 20.4$)$ & 0.084 \\
\hline Benjangkapradit prostration & $2.6(-7.8$ to 13.7$)$ & $6.3(-10.3$ to 24.9$)$ & 0.054 \\
\hline Cross-legged & 29.9 (10.4 to 44.3$)$ & 28.4 (9.9 to 45.7$)$ & 0.619 \\
\hline \multicolumn{4}{|l|}{ Left-monk } \\
\hline Left hip & $15.1(-6.4$ to 44.7$)$ & $22.8(-3.7$ to 55.8$)$ & $0.043^{*}$ \\
\hline Right hip & $6.6(-4.8$ to 21.8$)$ & $16.1(-5.0$ to 30.7$)$ & $0.024^{*}$ \\
\hline \multicolumn{4}{|l|}{ Right-monk } \\
\hline Left hip & $5.0(-7.5$ to 20.6$)$ & $11.2(-8.5$ to 29.4$)$ & 0.113 \\
\hline Right hip & $14.4(-8.4$ to 37.8$)$ & $20.2(1.8$ to 38.9$)$ & $0.034^{*}$ \\
\hline Squatting & $7.6(-6.5$ to 24.2$)$ & $11.8(-5.1$ to 34.3$)$ & 0.475 \\
\hline Sitting on a step stool & $6.4(-6.0$ to 23.1$)$ & $14.6(-3.4$ to 31.5$)$ & $0.018^{*}$ \\
\hline Figure-four & 15.8 (10.1 to 28.7$)$ & 17.9 (2.5 to 35.2$)$ & 0.396 \\
\hline Standard leg-cross & $-13.7(-21.7$ to 3.9$)$ & $-6.0(-19.9$ to 6.7$)$ & $<0.001^{*}$ \\
\hline \multicolumn{4}{|c|}{ External rotation $(+) /$ Internal rotation $(-)$} \\
\hline Kneeling plantar-flexed & $1.19(-6.3$ to 16.63$)$ & $1.8(-8.1$ to 20.8$)$ & 0.627 \\
\hline Kneeling dorsi-flexed & $6.7(-8.3$ to 22.0$)$ & $9.9(1.8$ to 17.9$)$ & 0.136 \\
\hline Benjangkapradit prostration & $1.2(-12.7$ to 12.1$)$ & $6.7(-18.2$ to 15.5$)$ & 0.301 \\
\hline Cross-legged & 64.4 (37.6 to 81.7 ) & 57.8 (40.7 to 80.5$)$ & 0.051 \\
\hline \multicolumn{4}{|l|}{ Left-monk } \\
\hline Left hip & $-36.6(-54.5$ to -15.5$)$ & $-37.5(-53.4$ to -5.2$)$ & 0.860 \\
\hline Right hip & 50.4 (33.9 to 62.2$)$ & $47.2(18.7$ to 62.5$)$ & 0.166 \\
\hline \multicolumn{4}{|l|}{ Right-monk } \\
\hline Left hip & 49.5 (37.1 to 58.9$)$ & $46.2(27.7$ to 54.1$)$ & $0.036^{*}$ \\
\hline Right hip & $-37.0(-52.3$ to -9.9$)$ & $-36.3(-51.9$ to -4.7$)$ & 0.852 \\
\hline Squatting & $-3.4(-23.7$ to 7.7$)$ & $-6.3(-24.5$ to 4.0$)$ & 0.128 \\
\hline
\end{tabular}


Table 4 The measured kinematics of the hips of all participants, stratified by BMI (Continued)

\begin{tabular}{|c|c|c|c|}
\hline $\begin{array}{l}\text { Kinematic data of each } \\
\text { sitting position }\end{array}$ & $\begin{array}{l}\text { Non-overweight } \\
\text { Median (range) } \\
\text { degrees } \\
(n=26) \\
\end{array}$ & $\begin{array}{l}\text { Overweight } \\
\text { Median (range) } \\
\text { degrees } \\
(n=22)\end{array}$ & $P$ value \\
\hline Sitting on a step stool & $-4.6(-15.9$ to 6.8$)$ & $-7.6(-15.7$ to 9.3$)$ & 0.069 \\
\hline Figure-four & 59.1 (42.9 to 68.9) & 51.6 (35.1 to 75.7$)$ & 0.072 \\
\hline Standard leg-cross & 27.4 (2.9 to 45.2$)$ & 26.7 (12.9 to 63.7$)$ & 0.555 \\
\hline
\end{tabular}

The $P$ values were for the Mann-Whitney $U$ test.

The asterisk $\left({ }^{*}\right)$ denotes a statistically significant difference between two groups.

right- and left-monk sitting positions (both the left and the right hips were analyzed for those 2 sitting positions). The subjects performed each sitting position three times to calculate the mean and reliability of the measurement, and they were allowed to move their body to feel comfortable between each execution at least one minute break.

During the measurements, the subjects sat on a cushion to not only mitigate discomfort and but to lift the limbs above the floor. An Asian low-style chair (7-in./ 18-cm height) was used for the sitting-on-a-step-stool position (Fig. 1H). For the figure-four and standard-leg- cross positions, however, a standard plastic chair (18-in./ 46-cm height) was employed (Fig. 1I-J).

\section{Statistical analysis}

The calculation of the sample size was based on the primary outcome, the ROM of squatting with heels down. It used the minimum, clinically meaningful, difference approximation, which was based on expert opinion. This was estimated to be 10 degrees (i.e., a target difference of 9 degrees). Using a two-sided Student's t-test, an $80 \%$ power to detect a difference in the ROM of squatting

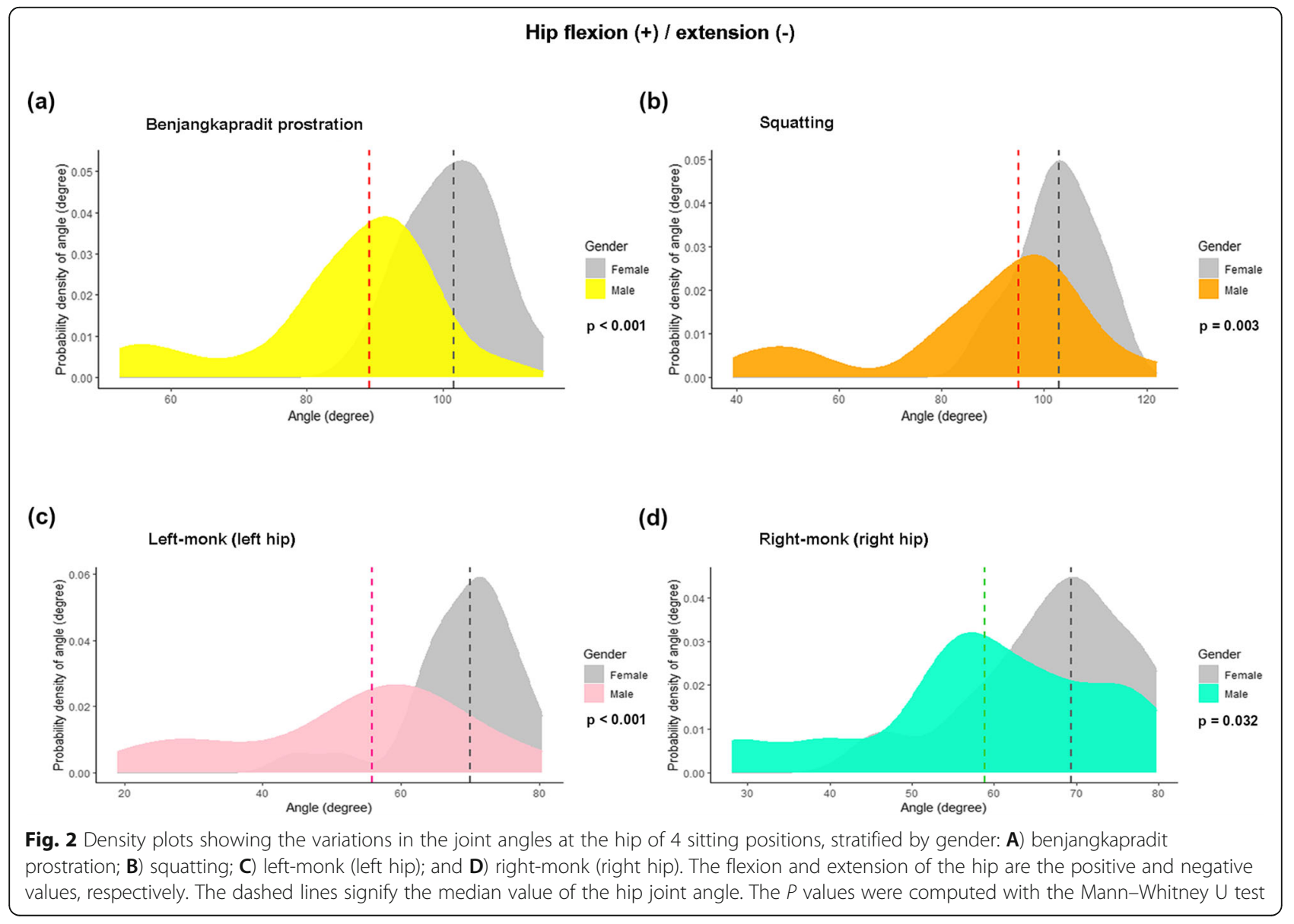




\section{Hip flexion (+) / extension (-)}

(a)

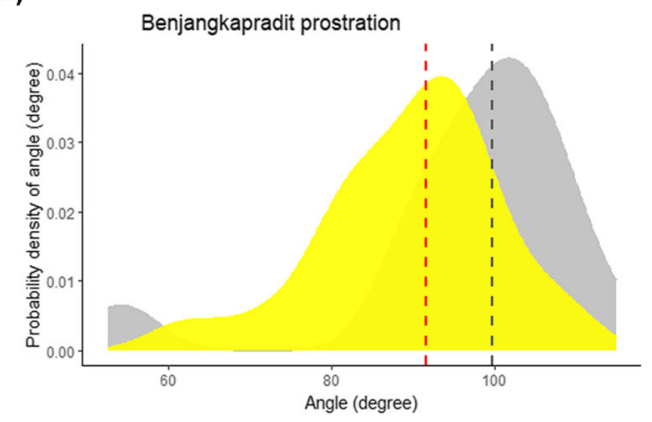

(c)

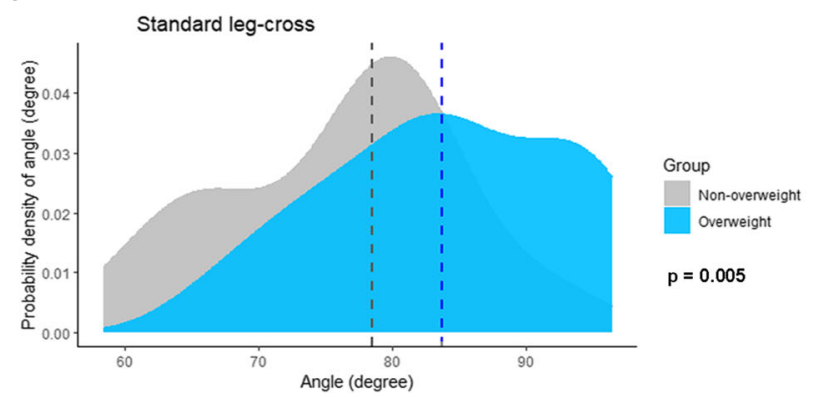

(b)

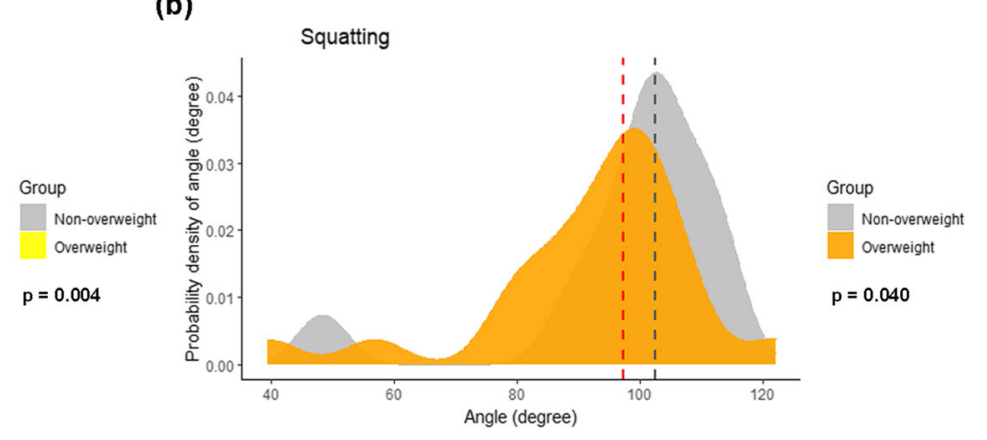

Fig. 3 Density plots showing the variations in the joint angles at the hip of 3 sitting positions, stratified by BMl (overweight, BMI $\geq 23 \mathrm{~kg} / \mathrm{m} 2$ ): A) benjangkapradit prostration; B) squatting; and $\mathbf{C}$ ) standard leg-cross. The flexion and extension of the hip are the positive and negative values, respectively. The dashed lines signify the median value of the hip joint angle. The $P$ values were computed with the Mann-Whitney $U$ test

with heels down of 9 degrees $(\mathrm{SD}=11.0$ from a previous study), [7] a 5\% level of significance required a sample size of 24 participants per group. A total of 48 subjects were therefore recruited.

The primary outcome was the kinematics of the hip ROMs of 10 sitting positions. Continuous data were described with mean and standard deviation (SD), and median and range; frequency and percentage were used for categorical data. Intraclass correlation coefficient (ICC) was used to present the intrarater reliability of the measurements. The ICCs were determined using a two-way mixed-effects model and single rater $(\mathrm{ICC} 3,1)$ with absolute agreement. ICC values were interpreted as follows: less than 0.5 as "poor"; 0.50 to 0.75 as "moderate"; 0.75 to 0.90 as "good"; and more than 0.90 as "excellent" [16]. Differences between groups (male and female; and nonoverweight and overweight) were analyzed with the Chisquared test for categorical data, and with Student's ttest or the Mann-Whitney U test for continuous data. Density plots were constructed, and statistical analyses were performed using the statistical software SPSS for Windows (version 18.0; SPSS Inc., Chicago, IL, USA) and $\mathrm{R}$ version 4.0.3 ( $\mathrm{R}$ Foundation for Statistical
Computing, Vienna, Austria). The level of significant difference was set at 0.05 .

\section{Results}

The study included 48 participants (24 males and 24 females). Their demographic data is listed in Table 1. The males were taller and heavier, and had higher BMIs, than the females $(P$ value $<0.001$; Table 1$)$. Most of the participants had a dominant right leg (45 participants; 93.8\%). The participants were subdivided into 2 weight groups: non-overweight $(\mathrm{BMI}<23 \mathrm{~kg} / \mathrm{m} 2)$ and overweight (BMI $\geq 23 \mathrm{~kg} / \mathrm{m} 2$ ), in accordance with the cutoff values for the Asian population [17]. The overweight group comprised 22 participants, 18 (75\%) of whom were male (Table 2).

The data demonstrated the kinematics of hip angles in all 3 planes (flexion/extension; abduction/adduction; and internal and external rotation) in 10 sitting positions. The measurements were stratified by gender and weight (Tables 3 and 4, respectively). For the hip ROM in the sagittal plane, the hip flexion angle varied between sitting positions. Squatting showed the highest flexion angle $\left(99.7^{\circ} ; 47.3^{\circ}-122^{\circ}\right.$; Table 3$)$. There was a trend 


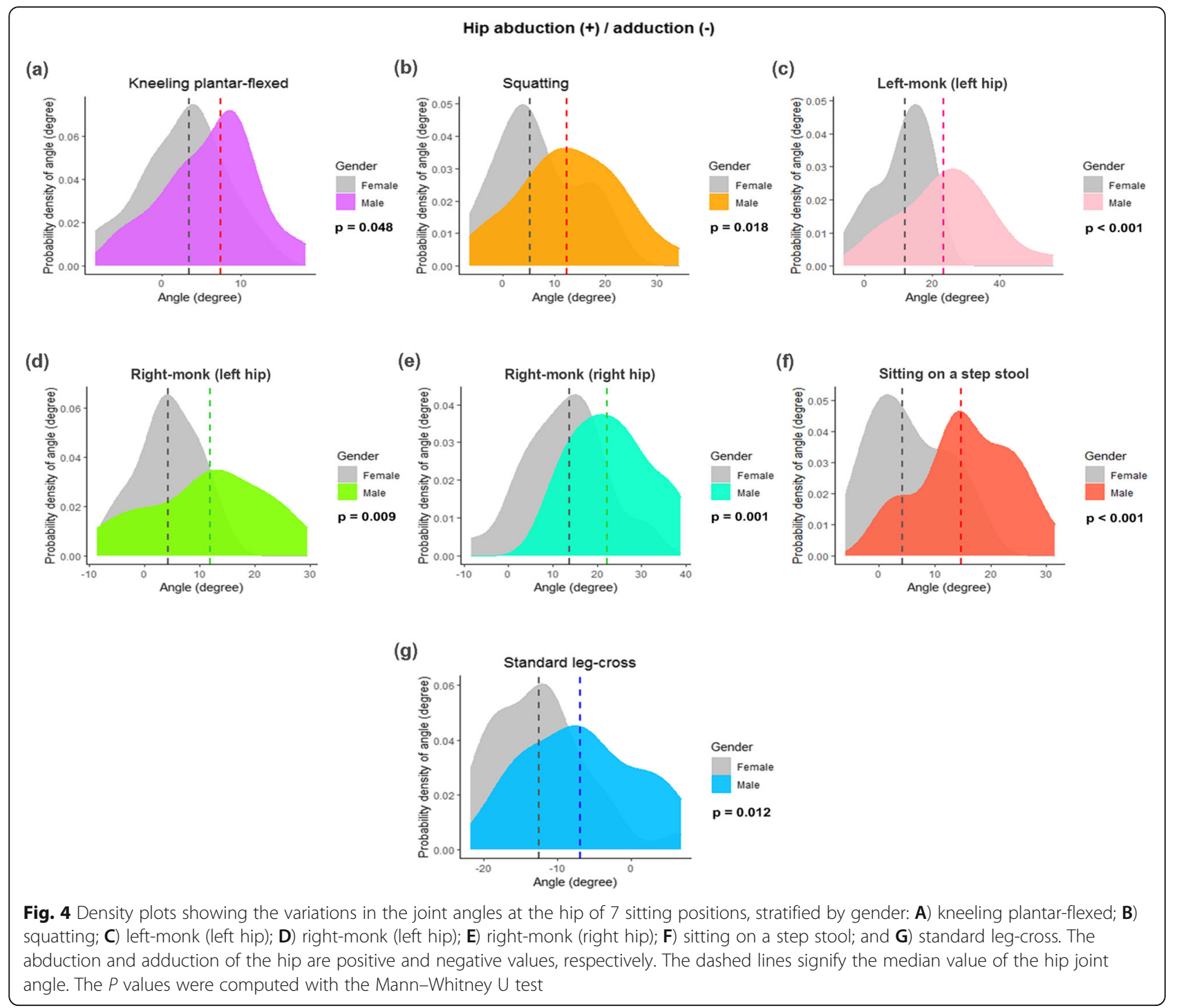

toward a higher flexion angle among the females than the males. Four out of the 10 sitting positions (Benjangkapradit prostration; left-monk position (left hip); rightmonk position (right hip); and squatting) had statistically significant differences between the genders (Table 3). Density plots showing the distribution of the flexion angles for those 4 sitting positions, stratified by gender, are presented at Fig. 2. As to BMI, the flexion angles were smaller for the overweight group than the nonoverweight group (Table 4 and Fig. 3).

In the frontal plane, there were more hip abduction angles in males than in females, with 6 out of 9 sitting positions demonstrating a statistically significant difference (Table 3 and Figs. 4A-F). There was also a trend for more abduction angles in the overweight group: 5 out of 9 sitting positions had a $P$ value $<0.05$ (Table 4 and Fig. 5). The cross-legged position had the highest abduction angle $\left(28.9^{\circ} ; 9.9^{\circ}-45.7^{\circ}\right)$. The standard legcross position was the only one that represented hip adduction of $10.5^{\circ}\left(-6^{\circ}\right.$ to $\left.21.7^{\circ}\right)$. Significantly more adduction angles were found in the female group than the non-overweight group, with a $P$ value $<0.05$ (Figs. 4G and $5 \mathrm{~F}$ and $\mathrm{G})$.

The kinematic data of the transverse plane revealed that the heterogeneity of the rotational angles depended on the sitting position (Tables 3 and 4, and Fig. 6). The right-monk (left hip) position showed more external rotation angles in the non-overweight group (Fig. 7). The cross-legged position had the highest external rotation angle $\left(62^{\circ} ; 37.6^{\circ}-81.7^{\circ}\right)$, while the left-monk position (left hip) had the highest internal rotation angle $\left(37.5^{\circ} ; 5.2^{\circ}-\right.$ $54.5^{\circ}$; Tables 3 and 4$)$. Intrarater reliability of measurements in this study showed good to excellent, with ICC values ranging from 0.82 to 0.98 . 


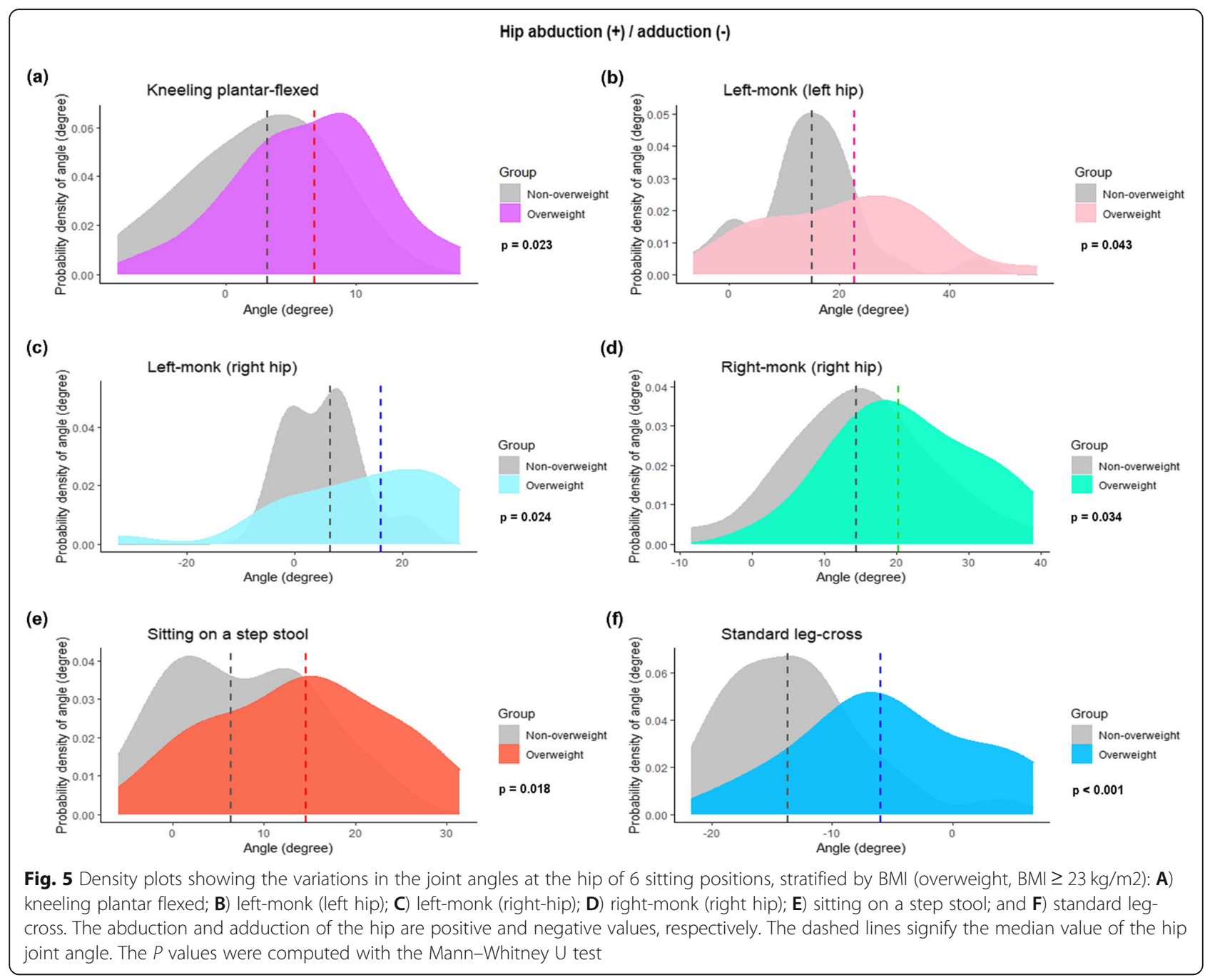

\section{Discussion}

This study focused on the kinematic data of the hip motions of 10, common, Asian sitting positions. The significant finding was that, of the 10 positions, squatting showed the highest flexion angle $\left(99.7^{\circ} ; 47.3^{\circ}-122^{\circ}\right)$. Our finding was similar to that of research on Indian subjects. That work investigated 5 sitting positions: squatting with the heels down; squatting with the heels up; kneeling dorsi-flexed; kneeling plantar-flexed; and crosslegged. The Indian study found that squatting with the heels down produced the maximum hip flexion angle $\left(95.4^{\circ} \pm 27^{\circ}\right)$ [7]. Squatting is best defined as the position where the foot contacts the ground in a way that brings the body down over the foot, requiring maximum hip flexion. Many ADLs require the squat position, such as toileting (especially with Asian-style toilets) [1]. In Western countries, the basic squat and chair squat are functional, multi-joint exercises that generate maximum hip flexion (particularly the chair squat) [18].
In this study, the cross-legged sitting position had the highest abduction angle $\left(28.9^{\circ} ; 9.9^{\circ}-45.7^{\circ}\right)$ and external rotation angle $\left(62^{\circ} ; 37.6^{\circ}-81.7^{\circ}\right)$. The crosslegged position is also known as the "crossed-legged tailor" position and the "Buddha" position. In Thailand, it is commonly used for resting, eating on a floor, or leisure activities such as yoga [1]. Moreover, the ability to sit cross-legged is one of the functional outcomes employed to evaluate patients after a total hip arthroplasty [19]. The study on the Indian population performing the cross-legged sitting posture found a mean abduction angle of $39^{\circ}\left(19^{\circ}-57^{\circ}\right)$ and a mean external rotation angle of $49^{\circ}\left(42^{\circ}-58^{\circ}\right)$ [10]. That work found more hip abduction angles and fewer external rotation angles than our study. However, the Indian research used a simple manual goniometer to measure angles; those values would be less accurate than ones obtained with 3DMA equipment, especially for rotational angles [20]. In comparison, a 
Hip external rotation (+)/ internal rotation (-)

(a)

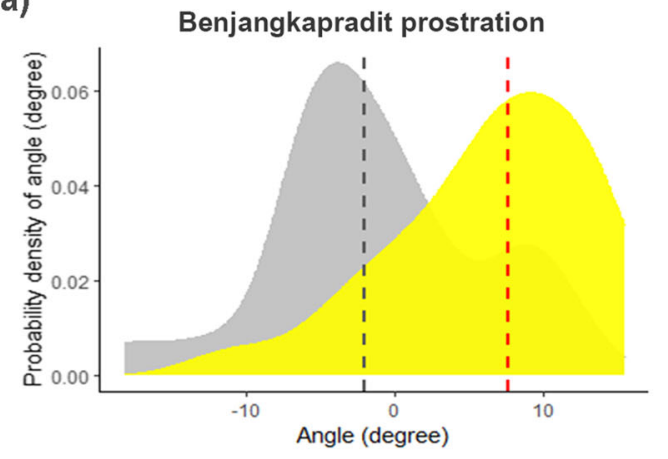

(c)

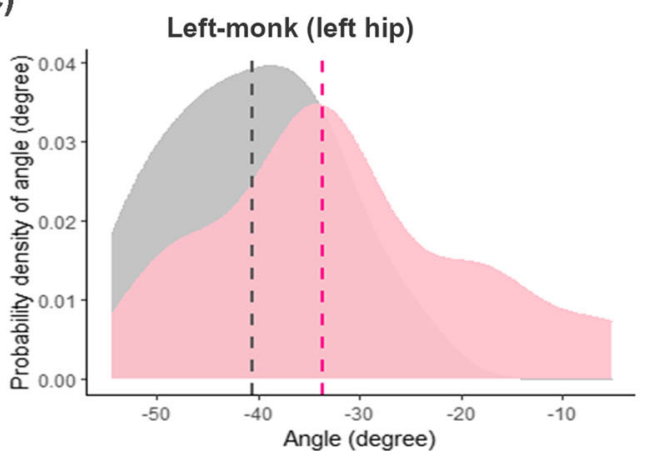

(b)

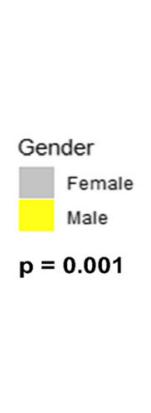

(d)

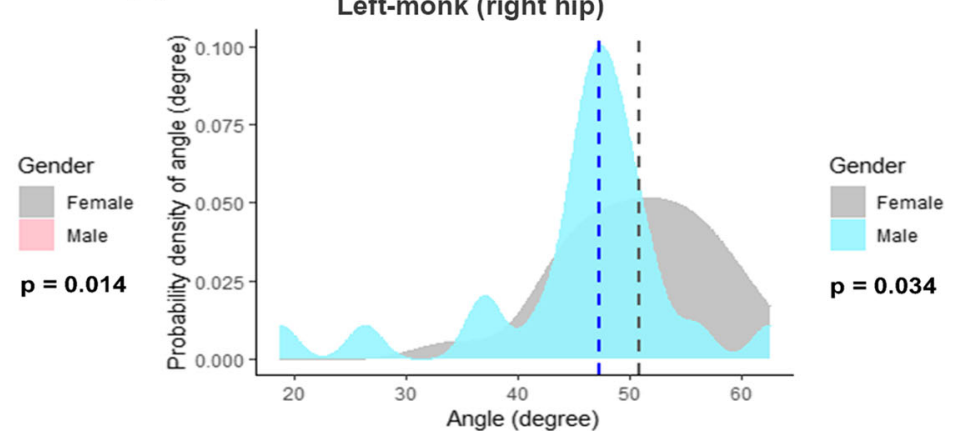

Fig. 6 Density plots showing the variations in the joint angles at the hip of 4 sitting positions, stratified by gender: A) benjangkapradit prostration; B) sitting on a step stool; C) left-monk (left hip); and $\mathbf{D}$ ) left-monk (right hip). The external and internal rotations of the hip are the positive and negative values, respectively. The dashed lines signify the median value of the hip joint angle. The $P$ values were computed with the Mann-Whitney U test

kinematic study of Chinese people found a median abduction angle of $12.7^{\circ}\left(1.3^{\circ}-32.7^{\circ}\right)$ and a median external rotation angle of $2.3^{\circ}\left(-11.9^{\circ}-36.4^{\circ}\right)$. Those values are much lower than the corresponding ones from our study [8]. The Chinese study subjects were instructed to sit cross-legged with a foam cushion only underneath their buttocks, not at the leg and foot areas. However, that particular way of sitting cross-legged is not commonly used for the performance of Asian-style ADLs. It might also lower the hip abduction and external rotation angles.

The authors of the current investigation found that the hip ROMs were associated with both gender and being overweight. There were more flexion angles (4 out of $10)$ and fewer abduction angles (6 out of 9 ) in the female group, with a $P$ value $<0.05$. However, there was no direct relationship between gender and rotational angles. The hip rotational ROM depended on the sitting position. In the case of the overweight subjects, there were fewer hip flexion angles and more hip abduction angles, with 5 out of 9 sitting positions having a $P$ value $<0.05$.
The kinematic data of the transverse plane showed the heterogeneity of the rotational angles depended on the sitting position. In a kinematic study, Huffman et al. investigated the effects of higher BMI on hip ROM [21]. They demonstrated that, during the sitting and sit-tostand postures, there was a greater increase in the peak abduction angle for their high-BMI group than for their normal subjects [21]. We believe that the lower hip flexion ROM of the overweight group in the current research may have been connected with a higher level of posterior thigh tissue (indicated by the greater thigh circumference of those subjects) as well as movement while changing position. To our knowledge, no study has previously focused on the associations between either gender or weight group and the hip ROMs during the sitting positions used for the ADLs. However, one kinematic study compared the ROMs of young adults and the elderly while kneeling [9]. That work found no apparent differences in the knee and ankle joints of the 2 groups. Nevertheless, the research did find a higher maximum hip flexion angle for the elderly than the 


\section{Hip external rotation (+) / internal rotation (-)}
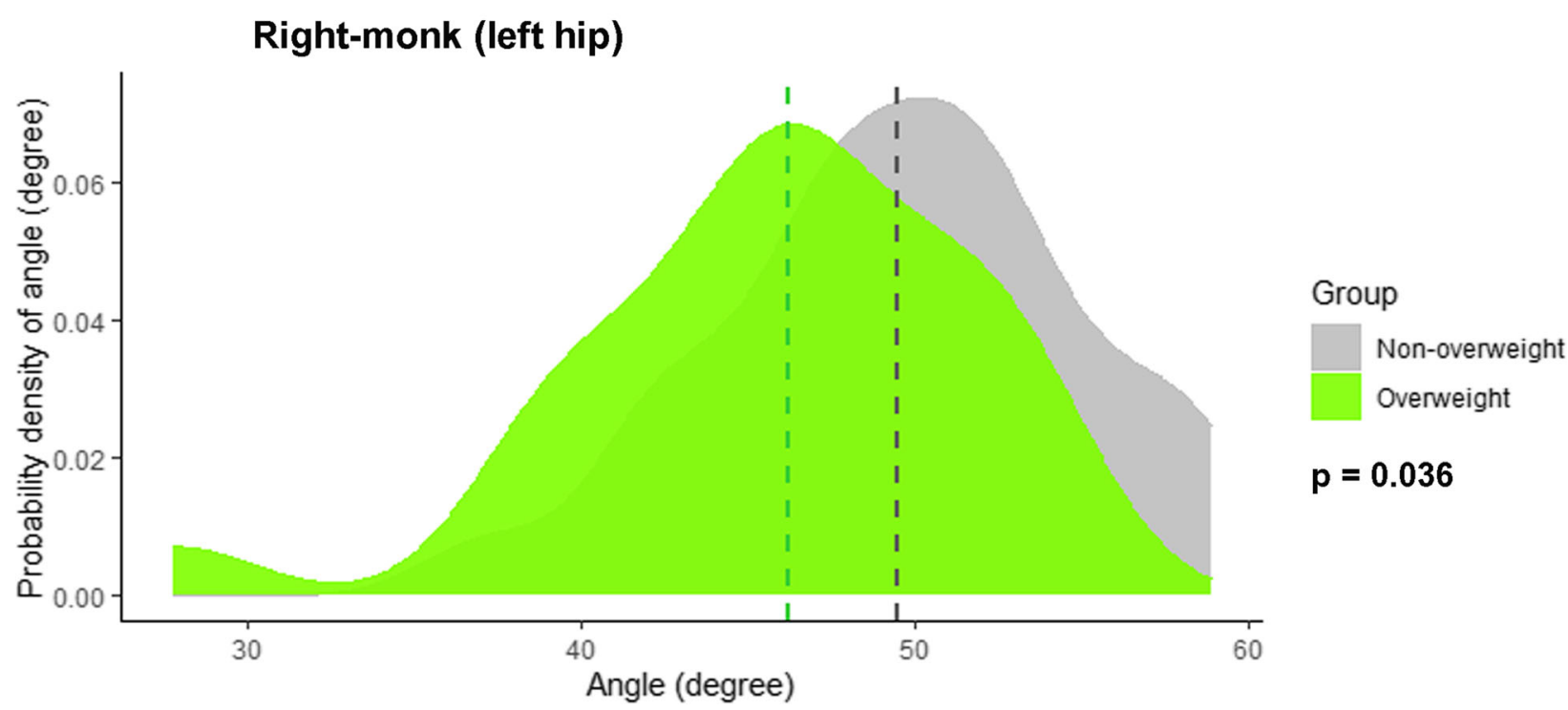

$p=0.036$

Fig. 7 Density plots showing the variations in the joint angles at the hip for a right-monk (left hip) position, stratified by BMI (overweight, BMI $\geq$ $23 \mathrm{~kg} / \mathrm{m} 2$ ). The external and internal rotations of the hip are the positive and negative values, respectively. The dashed lines signify the median value of the hip joint angle. The $P$ values were computed with the Mann-Whitney $U$ test

young adults $\left(100.5^{\circ}\right.$ and $67.5^{\circ}$, respectively) [9]. In the current study, the authors recruited healthy adults aged under 35 years. The age factor would therefore have been most unlikely to affect the main findings of our study. The authors suggest that all factors-gender, weight, and age-should be considered while determining the hip ROM for each sitting position used for the ADLs.

The increase in knowledge gained through kinematic data studies benefits various professional fields. For physiotherapists and prosthetists, gaining a better understanding of these functional motions might aid the development of prosthetic designs that meet the functional needs of patients (especially those in non-Western countries). Orthopedists can adapt the knowledge to treat patients both conservatively and surgically. Activity modification and the avoidance of aggravating activities are key to the conservative treatment of hip disorders. Labral tears and intra-articular hip pathologies are often associated with groin pain that is exacerbated by flexion and rotatory hip movements [22]. The symptoms experienced by femoroacetabular impingement syndrome patients are aggravated in the flexed, adducted, and internal rotated positions [23]. Patients diagnosed with subspine hip impingement suffer severe pain with hip flexion angles greater than 90 degrees [24]. Being aware of the reference values of the hip motions of each common sitting position will help with the education of patients who have hip disorders. In turn, it will assist them to minimize or prevent symptoms.

In order to apply kinematic data to patients who had undergone a total hip arthroplasty (THR), Miki et al. investigated the anatomical hip ROMs after THR using a navigation system [25]. They found a wide range of passive hip ROMs intraoperatively: $113^{\circ}$ of flexion, $46^{\circ}$ of abduction, $75^{\circ}$ of internal rotation, and $36^{\circ}$ of external rotation [25]. That research team then studied the patients immediately after their THRs to determine the effects, if any, of the anesthesia, muscle relaxants, surgical techniques, and implant designs that had been utilized. However, their reference values should be cautiously applied in clinical practice. Four sitting positions in the current study (cross-legged, figure-four, left-monk, and right- monk) demonstrated external rotation angles that were higher than the reference values determined by Miki and colleagues [25]. The differences between measuring methods and subjects may be the reasons why there are more external rotation angles in our study. Hence, patients who undergo THR should be cautioned about immediately using these 4 positions. Generally, surgeons will know the safe and stable hip ROMs in the operative theater. Understanding these data could prevent dangers, such as impingement or dislocation after sitting during the ADLs. Physical medicine and 
rehabilitation physicians might apply these data to design patients' postoperative protocols and prevent adverse events.

This study had several limitations. Firstly, there was a wide variety of ways in which the 10 sitting postures were executed and achieved. These might be the main reason for the high variety of hip angles in the study. The authors attempted to reduce variations by demonstrating the correct posture for each sitting position and allowing the participants to practice them before the trial. The maximum angle achieved for each sitting position was measured; this is where the use of a 3DMA system is superior to a static measuring device like a goniometer. Secondly, the accuracy of the measurement was the primary concern of this study. The authors chose the reflective skin markers and firmly attached them to the participant's anatomical landmarks. Using pins or other devices as the bone markers would be more accurate than the skin markers. However, those devices are more suitable for cadaveric studies and could not be used in routine clinical practice. The authors try to solve these problems by measuring each sitting position three times each and ensuring that all markers were perfectly set in the anatomical landmarks during the angle calculation. Moreover, the authors calculated the intra-rater reliability and showed good to excellent in this study. Thirdly, all subjects were young and healthy. These data do not cover elderly patients nor those with lower extremity disorders. Finally, the study regarded the hip angles as the intersegment angle between the pelvis axis and the thigh. No data were collected on spinopelvic parameters that might affect the hip joint while changing position. However, as all subjects in the study were healthy volunteers, the authors believe that all would have normal spinopelvic mobility. The pelvic tilt is an interesting variable for further research as it might affect the sitting posture of patients with pathologies of the spine and/or hip.

\section{Conclusions}

This study provided the functional hip motions of common Asian sitting positions. These kinematic data can be applied in clinical practice as reference values to determine safe positions. Gender and being overweight affected the hip angles in both the sagittal and frontal planes.

\section{Abbreviations}

BMI: body mass index; ADLs: activities in daily life; ROM: range of motion; 3DMA: three-dimensional motion analysis; ASIS: anterior superior iliac spine; SD: standard deviation; THR: total hip replacement

\section{Acknowledgements}

The authors gratefully thanks Mr. Wacharapol Tepa for a statistical analysis, Miss Waraporn Chalermsuk for graphic materials and Siriraj Research Development Fund, Bangkok, Thailand for supporting this study.

\section{Authors' contributions}

Conception and design: PG, PL and BV. Acquisition and analysis of data: PG, JC, PK, NS. PK performed and interpreted the three-dimensional motion analysis data. Authors participate in drafting in drafting the article: PG and JC. Authors participate in reviewing the manuscript: PL and BV. BV as the project administration and substantially edited the manuscript. I attest to the fact that all authors listed on the title page have read and approved the manuscript, attest to the validity and legitimacy of the data and its interpretation, and agree to its submission to "BMC Musculoskeletal Disorders" for an evaluation and reviewing for maybe publishing.

\section{Funding}

This study was funded by a grant (R016131012) from the faculty of Medicine Siriraj Hospital, Mahidol University, Bangkok, Thailand.

\section{Availability of data and materials}

The datasets used and/or analyzed during the current study are available from the corresponding author on reasonable request.

\section{Declarations}

Ethics approval and consent of participate

This study was approved by the Siriraj Institutional Review Board, and it is in full compliance with international guidelines for human research protection, such as the Declaration of Helsinki, the Belmont Report, and the International Conference on Harmonization in Good Clinical Practice; COA no. Si 508/2017. Prior to its commencement, all participants read an information sheet and gave written informed consent.

\section{Consent for publication}

Not applicable.

\section{Competing interests}

The authors declare that there are no conflicts of interest related to this study.

Received: 9 May 2021 Accepted: 22 June 2021

Published online: 12 July 2021

\section{References}

1. Mulholland SJ, Wyss UP. Activities of daily living in non-Western cultures: range of motion requirements for hip and knee joint implants. Int J Rehabil Res. 2001;24(3):191-8. https://doi.org/10.1097/00004356-200109000-00004.

2. Hoaglund FT, Yau AC, Wong WL. Osteoarthritis of the hip and other joints in southern Chinese in Hong Kong. J Bone Joint Surg Am. 1973;55(3):54557. https://doi.org/10.2106/00004623-197355030-00010.

3. Ahlberg A, Moussa M, Al-Nahdi M. On geographical variations in the normal range of joint motion. Clin Orthop Relat Res. 1988;234:229-31.

4. Johnston RC, Smidt GL. Hip motion measurements for selected activities of daily living. Clin Orthop Relat Res. 1970;72:205-15.

5. Davis KE, Ritter MA, Berend ME, Meding JB. The importance of range of motion after total hip arthroplasty. Clin Orthop Relat Res. 2007;465:180-4. https://doi.org/10.1097/BLO.0b013e31815c5a64.

6. Beck M, Kalhor M, Leunig M, Ganz R. Hip morphology influences the pattern of damage to the acetabular cartilage: femoroacetabular impingement as a cause of early osteoarthritis of the hip. J Bone Joint Surg Br. 2005;87(7): 1012-8.

7. Hemmerich A, Brown H, Smith S, Marthandam SS, Wyss UP. Hip, knee, and ankle kinematics of high range of motion activities of daily living. J Orthop Res. 2006;24(4):770-81. https://doi.org/10.1002/jor.20114.

8. Zhou H, Liu A, Wang D, Zeng X, Wei S, Wang C. Kinematics of lower limbs of healthy Chinese people sitting cross-legged. Prosthetics Orthot Int. 2013; 37(5):369-74. https://doi.org/10.1177/0309364612470964.

9. Zhou H, Wang DM, Liu TR, Zeng XS, Wang CT. Kinematics of hip, knee, ankle of the young and elderly Chinese people during kneeling activity. J Zhejiang Univ Sci B. 2012;13(10):831-8. https://doi.org/10.1631/jzus.B11003 55.

10. Kapoor A, Mishra SK, Dewangan SK, Mody BS. Range of movements of lower limb joints in cross-legged sitting posture. J Arthroplast. 2008;23(3): 451-3. https://doi.org/10.1016/j.arth.2007.04.008. 
11. Bell AL, Brand RA, Pedersen DR. Prediction of hip joint Centre location from external landmarks. Hum Mov Sci. 1989;8(1):3-16. https://doi.org/10.1016/01 67-9457(89)90020-1.

12. Bell AL, Pedersen DR, Brand RA. A comparison of the accuracy of several hip center location prediction methods. J Biomech. 1990;23(6):617-21. https:// doi.org/10.1016/0021-9290(90)90054-7.

13. Assi A, Sauret C, Massaad A, Bakouny Z, Pillet H, Skalli W, et al. Validation of hip joint center localization methods during gait analysis using 3D EOS imaging in typically developing and cerebral palsy children. Gait Posture. 2016;48(7):30-5. https://doi.org/10.1016/j.gaitpost.2016.04.028.

14. Davis RB, Õunpuu S, Tyburski D, Gage JR. A gait analysis data collection and reduction technique. Hum Mov Sci. 1991;10(5):575-87. https://doi.org/10.101 6/0167-9457(91)90046-Z.

15. van Melick N, Meddeler BM, Hoogeboom TJ, Nijhuis-van der Sanden MWG, van Cingel REH. How to determine leg dominance: The agreement between self-reported and observed performance in healthy adults. PLoS One. 2017;12(12):e0189876.

16. Koo TK, Li MY. A guideline of selecting and reporting Intraclass correlation coefficients for reliability research. J Chiropr Med. 2016;15(2):155-63. https:// doi.org/10.1016/j.jcm.2016.02.012.

17. Dhiman RK, Duseja A, Chawla Y. Asians need different criteria for defining overweight and obesity. Arch Intern Med. 2005;165(9):1069-70. https://doi. org/10.1001/archinte.165.9.1069-b.

18. Flanagan S, Salem GJ, Wang MY, Sanker SE, Greendale GA. Squatting exercises in older adults: kinematic and kinetic comparisons. Med Sci Sports Exerc. 2003;35(4):635-43. https://doi.org/10.1249/01.MSS.0000058364.47973. 06.

19. Imam MA, Fathalla I, Holton J, Nabil M, Kashif F. Cementless Total hip replacement for the Management of Severe Developmental Dysplasia of the hip in the middle eastern population: a prospective analysis. Front Surg. 2016;3:31.

20. Roach S, San Juan JG, Suprak DN, Lyda M. Concurrent validity of digital inclinometer and universal goniometer in assessing passive hip mobility in healthy subjects. Int J Sports Phys Ther. 2013;8(5):680-8.

21. Huffman KD, Sanford BA, Zucker-Levin AR, Williams JL, Mihalko WM Increased hip abduction in high body mass index subjects during sit-tostand. Gait Posture. 2015;41(2):640-5. https://doi.org/10.1016/.gaitpost.2015. 01.014 .

22. Martin HD, Shears SA, Palmer IJ. Evaluation of the hip. Sports Med Arthrosc Rev. 2010;18(2):63-75. https://doi.org/10.1097/JSA.0b013e3181dc578a.

23. Amanatullah DF, Antkowiak T, Pillay K, Patel J, Refaat M, Toupadakis CA, et al. Femoroacetabular impingement: current concepts in diagnosis and treatment. Orthopedics. 2015;38(3):185-99. https://doi.org/10.3928/0147744 7-20150305-07.

24. Nabhan DC, Moreau WJ, McNamara SC, Briggs KK, Philippon MJ. Subspine hip impingement: an unusual cause of hip pain in an elite weightlifter. Curr Sports Med Rep. 2016;15(5):315-9. https://doi.org/10.1249/JSR. 0000000000000291.

25. Miki H, Yamanashi W, Nishii T, Sato Y, Yoshikawa H, Sugano N. Anatomic hip range of motion after implantation during total hip arthroplasty as measured by a navigation system. J Arthroplast. 2007;22(7):946-52. https:/ doi.org/10.1016/j.arth.2007.02.004

\section{Publisher's Note}

Springer Nature remains neutral with regard to jurisdictional claims in published maps and institutional affiliations.

Ready to submit your research? Choose BMC and benefit from:

- fast, convenient online submission

- thorough peer review by experienced researchers in your field

- rapid publication on acceptance

- support for research data, including large and complex data types

- gold Open Access which fosters wider collaboration and increased citations

- maximum visibility for your research: over $100 \mathrm{M}$ website views per year

At BMC, research is always in progress.

Learn more biomedcentral.com/submissions 